\title{
Irrelevant stimuli present all or half of the time as subsequent discriminanda'
}

SALLY E, SPERLING

UNIVERSITY OF CALIFORNIA, RIVERSIDE

Irrelevant stimuli each associated with a $50 \%$ reinforcement schedule were either present on all or on half of initial discrimination training trials. For different groups in test problem training a previously irrelevant stimulus was either the positive or the negative discriminandum, with a novel stimulus as the other discriminandum, or both discriminanda were novel stimuli. No effect due to novelty was demonstrable. Ss were retarded in test learning if their test negative discriminandum had been present on half of the initial acquisition trials; no other groups differed from controls.

It is now clear that stimuli may acquire discriminative control over responding even though the reinforcement schedules associated with their presence differ from the conventional $100 \%$ or $0 \%$ (e.g.. Babb, 1956; Jeeves \& North, 1956; Sperling, 1962, for previously irrelevant cues as subsequent discriminanda; Erlebacher, 1963; Grosslight, Hall, \& Scott, 1954; Kendler \& Lachman, 1958; North \& McDonald, 1962; Pavlik \& Born, 1963, for discrimination learning with intermittent schedules of reinforcement for responses to the positive discriminandum, the negative discriminandum, or both). However, the specific conditions under which irrelevant stimuli become discriminative are not specifiable from these data; the present experiment was designed to examine some of these conditions.

Method

The Ss were 46 naive male hooded rats, approximately 90 days of age. The data for two additional Ss were discarded since they died during the experiment.

The apparatus was two elevated platforms enclosed in a cubicle compartment divided by a partition into starting and stimulus sections. When $\mathrm{S}$ broke an infrared light beam at the terminal end of the starting platform, a 100-w bulb over the stimulus compartment was turned on and a timer was started which stopped when $\mathrm{S}$ stepped off the stimulus platform.

A $20 \mathrm{-v}$ light bulb centered on a swinging door at the terminal end of the platform could be either on (L) or off (D). Four different stimulus platforms covered with 1 in. Mystic Tape were used: Checkerboard (C) made of alternating black and white squares; Stripe (S) made of alternating longitudinally laid black and white tape; Zigzag ( $\mathrm{Z}$ ) made of alternating black and white diagonals laid from the longitudinal center; and Gray (G) made of longitudinally laid gray tape. The ratio of black to white in the areas of the first three platforms was about equal within and among platforms.

A $23 \mathrm{hr}$.deprivation schedule was maintained through- out 12 days of pretraining and the experiment. All Ss received initial training on a $(L+D-)$ discrimination problem to a criterion of not more than one trial in a day on which the latency of response in the presence of the negative discriminandum was shorter than any latency of response in the presence of the positive discriminandum. There were six positive and six negative trials per day in random order on a $10-\mathrm{min}$. intertrial interval. A food cup was baited with two 94 mg Noyes pellets on positive trials; it was not present on negative trials.

Subgroups of Ss had different stimulus platforms present during this training. For Group $C(N=16)$ the C platform was present on each trial; for Group Z $(N=14)$ the $Z$ pattern was present on each trial; for Group $\mathrm{CZ}(\mathrm{N}=8)$ the $\mathrm{C}$ platform was present on half of the $L$ and half of the $D$ trials each day (three each) and the $\mathrm{Z}$ platform was present on the other trials; for Group CS $(\mathrm{N}=8)$ the arrangement was the same except that the $\mathrm{S}$ platform was used in place of the $\mathrm{Z}$.

On the day following their criterion day on the $L$ vs. D problem, each $\mathrm{S}$ began test problem learning. The swinging door containing the light bulb was removed from the apparatus. All procedures remained the same, and training was given to the acquisition criterion.

Half of the Ss were presented with a problem in which $C$ was the positive discriminandum and $G$ was the negative $(C+G-)$; for the other half of the Ss $S$ was positive and $\mathrm{C}$ negative $(\mathrm{S}+\mathrm{C}-)$. These groups were constituted as follows: Half of training Group $\mathrm{C}$ went into each test problem $(\mathrm{C} / \mathrm{C}+\mathrm{G}-)$ and $(\mathrm{C} / \mathrm{S}+\mathrm{C}-)$; half of training Group $\mathrm{Z}$ went into each problem; $(\mathrm{Z} / \mathrm{C}+\mathrm{G}-)$ and $(\mathrm{Z} / \mathrm{S}+\mathrm{C}-)$; training Group $\mathrm{CZ}$ was given the $\mathrm{S}$ vs. $\mathrm{C}$ problem $(\mathrm{CZ} / \mathrm{S}+\mathrm{C}-)$; and training Group $\mathrm{CS}$ was given the C vs. G problem (CS/S+G-).

Resulis

Mean trials to criterion for the two problems are presented in Table 1, ordered with respect to test learning. There were no differences among the six experimental groups on trials to criterion on the $L$ vs. $D$ problem $(F=2.14 ; d f=5 / 40 ; p>.05)$. An analysis of

Table 1. Mean Trials to Criterion on Acquisition and Test Problems

Groups

Problem $\left(C Z / S_{+} C_{-}\right)\left(C / C_{+} G_{-}\right)\left(C S / C_{+} G_{-}\right)\left(Z / S_{+} C_{-}\right)\left(C / S_{+} C_{-}\right)\left(Z / C_{+} G_{-}\right)$

Acquisition

$\begin{array}{llllll}\text { of } L+D-106.5 & 132.0 & 115.0 & 82.3 & 94.5 & 108.0\end{array}$

\begin{tabular}{lllllll} 
Test & $84.0^{\star}$ & 54.0 & 52.5 & 51.4 & 48.0 & 39.4 \\
\hline
\end{tabular}

* This mean is significantly different from each of the others in the row $(\underline{p}<.01)$ 
variance for test problem learning yielded $F=9.10$; $\mathrm{df}=5 / 40 ; \mathrm{p}<.001$. The differences between these means were tested by $99 \%$ confidence intervals using Tukey's test. Group ( $\mathrm{CZ} / \mathrm{S}+\mathrm{C}-)$ was significantly retarded in test problem learning compared to all of the other groups which did not differ from each other.

Analyses of transformed latency scores (log Iat) indicated that terminal acquisition response levels in the presence of the $\mathrm{C}$ and $\mathrm{Z}$ stimuli did not differ among the group. There was also no apparent difference in latency of response to $\mathrm{C}$ on the first day of test problem training (both Fs were less than one), even though $\mathrm{C}$ was a novel stimulus for two of these groups$(\mathrm{Z} / \mathrm{C}+\mathrm{C}-)$ and $(\mathrm{Z} / \mathrm{S}+\mathrm{C}-)$. Mean $\log$ lat for $\mathrm{S}$ and $\mathrm{G}$ on the first test day differed neither from each other $(F=1.27 ; d f=5 / 40 ; p>.20)$ nor from mean $\log$ lat for $C$ (difference $t=2.54 ; d f=5 ; p>.05$ )

Mean $\log$ lat within each group on the second test day indicated that only Group $(\mathrm{CZ} / \mathrm{S}+\mathrm{C}-)$ was still responding faster on negative than on positive trials. Discussion

If certain conditions of prior experience with a stimulus lead to the acquisition of discriminative control over responding by that stimulus, differences should be observable in the performance of groups who have had the necessary prior experience compared to those who have not. Neither Group $(\mathrm{Z} / \mathrm{C}+\mathrm{G}-)$ nor Group $(\mathrm{Z} / \mathrm{S}+\mathrm{C}-)$ had had any prior exposure to the two sets of test problem discriminanda. Group $(\mathrm{CZ} / \mathrm{S}+\mathrm{C}-)$ was the only experimental group which differed from them in test learning, and it was significantly slower.

Resistance to extinction in the presence of $\mathrm{C}$ seems to account for the retardation of this group which persisted longer in responding faster to $C$ than any other group. The discriminative coritrol over responding exhibited in resistance to extinction must have been acquired during initial training as a consequence of $\mathrm{C}$ being an intermittent feature of the initial environment. Group $(\mathrm{C} / \mathrm{S}+\mathrm{C}-)$ for which $\mathrm{C}$ was a constant feature also associated with a $50 \%$ reinforcement schedule did not show any effect in learning of the same test problem, and Group $(\mathrm{C} / \mathrm{C}+\mathrm{G}-)$ did not show any effect in learning a different test problem. These data, therefore, extend previous findings that a constant feature of the environment does not appear to acquire discriminative control over behavior (e.g., Ferster, 1951; Sperling \& Birch, 1960) and that a stimulus that has been one of two previously irrelevant stimuli on a $50 \%$ reinforcement schedule does acquire such control (Sperling, 1962).

However, $\mathrm{C}$ was also an intermittent feature of the initial environment for Group ( $\mathrm{CS} / \mathrm{C}+\mathrm{G}-)$ which received the same initial treatment with respect to $\mathrm{C}$ as did Group (CZ/S $+\mathrm{C}-$ ) but did not differ from the control groups in test learning. That it did not is perhaps an artifact of the test conditions for this group. Since Ss were responding asymptotically fast to the two discriminanda at the start of test learning, the mastery of the test problem was indexed primarily by increases in latency on ( $\left.\mathrm{G}^{-}\right)$trials rather than further decreases on $(\mathrm{C}+)$, thus making it unlikely that any effect of the initial treatment would be demonstrable in faster responding to $\mathrm{C}$. Therefore, these data seem most cleariy to suggest that resistance to extinction may provide a more sensitive index of prior treatment effects than acquisition functions in the single-stimulus apparatus. This has been observed previously (Birch, Ison, \& Sperling, 1960).

The lack of any observable effect due to novelty of the test stimuli argues against its contributing to the experimental results. The use of several different stimuli in different combinations for training and test argues against differential generalization gradients as contributing to the data.

\section{References}

Babb. H. Proportional reinforcement of irrelevant stimuli and transfer value. J. comp. physiol. Psychol., 1956, 49, 586-589.

Birch, D., Ison, J. R., \& Sperling, Sally E. Reversal learning under single stimulus presentation. J. exp. Psychol., 1960, 60, 36-40.

Erlebacher, A. Reversal learning in rats as a function of percentage of reinforcement and degree of learning. J. exp. Psychol, , 1963, 66, 84-90.

Ferster, C. B. The effect on extinction responding of stimuli continuously present during conditioning. J. exp. Psychol., 1951. 42, 443-449.

Grosslight, J. H., Hall, J. F., \& Scott, W. Reinforcement schedules in habit reversal: A confirmation. J. exp. Psychol., 1954, 48, 173-174.

Jeeves, M. A., \& North, A. J. Irrelevant or partially correlated stimuli in discrimination learning. $J$. exp. Psychol., 1956, 52, 90-94.

Kendler, H. H., \& Lachman, R. Habit reversal as a function of schedule of reinforcement and drive strength. J. exp. Psychol., $1958,55,584-591$

North, A. J., \& McDonald, R. D. Discrimination learning as a function of the probability of reinforcement. J. comp. physiol. Psychol., 1959, 52, 342-344.

Pavlik, W. G., \& Bom, D. G. Partial reinforcement effects in selective leaining. Psychol. Rep., 1962, 11, 575-580.

Sperling. Sally E. Extinction effects following nondifferential reinforcement of an irrelevan' stimilus. J. exp. Psychol., 1962, $63,50-56$.

Sperling, Sally E., \& Birch, D. Extinction effects under changed stimulus conditions following $50 \%$ and $100 \%$ reinforcement. Psychol. Rep., 1963, 12, 239-246.

\section{Note}

1. The experimental work was supported by grants from the National Science Foundation (G-24168) and the University of California, Riverside (5082). The author wishes to thank Keith Gutherz and Kenneth Hardy for their assistance in conducting the experiment. 